\title{
Professional Coordination in Cases of Child Maltreatment: Challenging Issues in Estonia, Finland, Slovenia and Spain. a Comparative Study
}

\author{
Elina Järvenpää \\ Finnish Rape Crisis Centre Tukinainen \\ Sandra Martínez-Molina \\ Polibienestar Research Institute (University of Valencia) \\ Jorge Garcés Ferrer \\ Polibienestar Research Institute (University of Valencia) \\ Barbara Haage \\ NGO Estonian Advice Centre \\ Mari-Liis Mänd, NGO Estonian Advice Centre \\ Špela Reš, Nora Institute Slovenia \\ Petra Belina, Nora Institute Slovenia \\ Boris Veler, Nora Institute Slovenia
}

Abstract

Child maltreatment can be considered as a general term that includes not only what is usually considered overt violence, but all forms of actions and neglect that have a negative impact on the child. When investigating cases of child maltreatment, various kinds of professionals are involved, including ones from the child protection authority, education and healthcare system and judiciary. To make sure that no child in need of assistance would go unnoticed and without help, the skill of co-operating is of high importance. Thus, changing of information between specialists is crucial to recognize the victims at early stage and gather as much information as possible to get the full picture of the situation. To this end, this paper analyses the situation in Estonia, Finland, Slovenia and Spain related to professionals' coordination challenges. Different methodology and instruments have been used such as desk research, focus groups, interviews and questionnaires to get an overview of the process in each country when child maltreatment cases are investigated. According to the results of the analyses, the main problems and areas which need improvement are quite similar in every country. Professionals intervening at a relatively late stage, the lack of time to co-operate and to discuss as well as and the lack of trust with other professionals can be regarded as the biggest problems in co-operation.

Keywords: child protection, child maltreatment, coordination, professional's challenges

\section{Introduction}

Child maltreatment can be considered as a general term that includes not only what is usually considered overt violence, but all forms of actions and neglect that have a negative impact on the child. When investigating cases of child maltreatment, various kinds of professionals are involved, including ones from the child protection authority, education and healthcare system and judiciary. To make sure that no child in need of assistance would go unnoticed and without help, the skill of cooperating is of high importance. Thus, changing of information between specialists is crucial to recognize the victims at early stage and gather as much information as possible to get the full picture of the situation. 
Given that situation, this paper analyses the situation in Estonia, Finland, Slovenia and Spain. Different methodology and instruments were used in each country in order to gather information to this situation analysis. Both primary and secondary resources were used get a wide description from every country's situation in the field of child protection.

This paper is divided into four main sections. The first section, the "Theoretical Framework" presents a general overview of child maltreatment definitions and relevant legislation of child protection system from every country, paying especial attention to the network of professionals and services that assist in situations of child abuse. The second section "Methodological issues" describes the methodology used in this study in each country. "The "Results" section, gathers the main findings obtained in each country regarding professionals' coordination when a case of child maltreatment occurs. Finally, the last section provides a summary of the main conclusions and ideas reached in this paper

\section{Theoretical Framework}

This section presents an overview of the most relevant legislation of child protection system in each country studied. Furthermore, this section describes the network of professionals and services involved when a case of child maltreatment occurs.

\section{Legislation}

Child protection is about putting the best interests of the child first. This principle is included in the United Nations Convention on the Rights of the Child, where Paragraph 1 of Article 3 states that the best interests of the child shall be a primary consideration in all actions concerning children, whether undertaken by public or private social welfare institutions, courts of law, administrative authorities or legislative bodies. Article 19 paragraph 1 states that a child must be protected against all physical and mental violence, injustice or abuse, negligence, careless or cruel treatment or exploitation, including sexual abuse. In addition, for example the EU Victims' Directive (2012/29/EU) has been adopted to strengthen the rights, support and protection of victims of crime. This international legal framework to protect children, reflected in numerous texts and international documents, has been a reference framework in developing child protection systems in European countries, although there are different legal frameworks related to children among European countries (Bartolomé, 2013).

In Estonia a new Child Protection Act came into force in Estonia on 01. 01. 2016. In the Child Protection Act it is brought out that a child in need of assistance is a child whose well-being is threatened or in the case of whom doubt has arisen concerning his or her abuse, neglect or any other situation violating the rights of the child and a child whose behavior threatens his or her well-being or the well-being of others. Paragraph 24 section 1 of the new Child Protection Act states that neglect of a child, mental, emotional, physical and sexual abuse of a child, including humiliation, frightening and physical punishment of a child, also punishment of a child in any other manner which endangers his or her mental, emotional of physical health is prohibited. According to paragraph 121 section 1 of the Penal Code, causing damage to the health of another person and physical abuse which causes pain is punishable. Paragraph 27 section 1 of the Child Protection Act states that all persons are required to report a child in need of assistance. The revised Act also brings forth the Child Helpline service telephone number (116 111) where people can call to notify about a child in need of assistance and it is also added that neither the person who reported the child in need of assistance nor the fact of notification will not be made public.

When working with cases of child maltreatment in Finland, various national laws are applied depending on the authorities involved at each level of the process. The key national laws referred to during the investigation are Child Welfare Act (417/2007), Act on Child Custody and Right of Access (361/1983), Criminal Code of Finland (39/1889), Act on Organising the Investigation of Crimes of Sexual Abuse and Violence Against Children (1009/2008) and Social Welfare Act (710/1982). The Child Welfare Act obliges professionals to notify the local authorities whenever they discover that there is a child for whom it is necessary to investigate the need for child welfare on account of the child's need for care, circumstances endangering the child's development, or the child's behaviour. Up until the year 1979, the Finnish Criminal Code allowed parents to use corporal punishment, and thus an assault made with an aim of 'educating' a child was not punishable. This has not been the case for almost 30 years now: in 1984, corporal punishment of children was banned in the Child Custody and Right of Access Act (361/1983). The Act on Child Custody and Right of Access prohibits oppressing, physically punishing or subjecting a child to any other form of abusive treatment. The Criminal Code of Finland prohibits sexual abuse of and violence against children. Still, however, determining what constitutes a punishable assault and what does not can cause problems and ambiguity in many cases (Heinonen, 2015). 
In Slovenia the Law on the Prevention of Domestic Violence regulates mutual exchange of information, co-operation and assistance between national organizations and non-governmental organizations, with the aim of prevention and assistance to child victims of violence. In addition, the Law on the Prevention of Domestic Violence defines preparation of Resolution on the national program of prevention of domestic violence for a period of five years. This resolution is a strategic document that sets out the objectives, measures and key policy makers to prevent and reduce domestic violence in the Republic of Slovenia.

In Spain the Spanish Constitution ${ }^{1}$ pays special attention to the fundamental rights and public liberties of all citizens including children. Specifically, the Constitution in article 39 establishes the comprehensive protection of children by public powers regardless of their affiliation, and parents' duty to provide assistance to their children both in and out of marriage until coming of age and in legally applicable cases. In the coordination area, Organic Law 8/2015 2enables the government to encourage the establishment of common criteria and minimum standards for the application of this law in the Autonomous Communities. Thus, this new legal framework intends to be a reference for the legislative development of the Autonomous Communities with the aim of guaranteeing uniform child protection in the entire territory, establishing the best interest of minors as a fundamental principle. Furthermore, Law 26/2015, 28th ${ }^{3} \mathrm{July}$, which modifies the child and adolescent protection system, reforms the system at various levels providing protection to child victims of any type of violence including foreign minors, regardless of their administrative situation. Among its diverse measures, the Law gives priorities stable measures over temporary ones and relatives over residential homes. In addition, this Law highlights for example the importance of a coordinated intervention in situations of risk, "with educational establishments and social and healthcare services, and where appropriate, with the collaborating entities from the respective territorial area or any others" (Article 17. 3).

\section{Description of the network of professionals assisting cases of child maltreatment in Estonia, Finland, Slovenia and Spain}

Generally speaking, the purpose of the network is to solve everyday problems of the person needing assistance and delimit relationships between certain people or groups (Martínez-Molina et al., 2016). According to Haage (2015), there are two modalities of networking. While the primary network is made up of parents, siblings, relatives, neighbours, and friends, the secondary network consists of various professionals. This last network is crucial if there is a case of child maltreatment as parents are not able to take care of their children and other institutions have to protect the minor (Department of Regional Education, 2011). Generally speaking, areas such as Education, Health, Social, Police, Legal and Philanthropic organizations work together in order to provide an integral attention to these situations, although networking can have different features in each country due to their child protection systems.

In particular, in Estonia there is a network of specialist, police, child protection workers and victim support workers in cases ensuring childrens' safety and rights. The police officers base their actions primarily on the interests and safety of the child when receiving information about a child in danger. Police officials co-operate with the local government (hereinafter KOV) child protective workers in case of a child in danger or in need of assistance. The police can immediately react and remove the threat when finding out about a child in danger or in need of assistance but future activities with the family primarily fall under the activities of the KOV specialists.

After ensuring the safety of the child the police official immediately contacts a KOV unit's child protection worker or an official responsible for child protection work who gives instructions for further actions. The police officer contacts the Department of Social Security's $24 / 7$ hotline in case it is not possible to get in contact with a child protection worker and a decision is made about placing the child in a social care facility. Considering and taking into account the child's safety, the police official may also decide to place the child in a social care facility on their own. However, it is highly recommended to first consult a specialist.

\footnotetext{
${ }^{1}$ Constitución Española. Boletín Oficial del Estado, 29 de diciembre de 1978, núm. 311, pp. 29313-29424.

2 Ley Orgánica 8/2015, de 22 de julio, de modificación del sistema de protección a la infancia y a la adolescencia. Boletín Oficial del Estado, 23 de julio de 2015, núm. 175, pp. 61871-61889.

3 Ley $26 / 2015$, de 28 de julio, de modificación del sistema de protección a la infancia y a la adolescencia. Boletín Oficial del Estado, 29 de julio de 2015, núm. 180, pp. 64544-64613.
} 
Police officers always assess the situation regarding child victims or children in danger in a way that the interests of the child are put first. The main purpose of all procedures involving children is to carry them out in a way that protects the child the most and is the least traumatizing to them. An important part of working with children is the co-operation between different structural units of the police, the prosecutor's office, local government, child protection specialists and victim support workers.

The Estonian Victim Support Act (2003) paragraph 3 section 1 points out that a victim support service is a public service that aims to maintain or better the subsistence of victims of crime, carelessness, ill-treatment, physical, mental or sexual violence. Victims of offense and their family members have the right to seek compensation for the cost of psychological care. According to a co-operation agreement signed by Police and Border Guard Board and Estonian National Social Insurance Board, the police send to the victim support worker leaflets about violence in intimate relationships including victim's contact information. A victim support worker contacts the victim based on the leaflet, gives necessary information and proposes a meeting.

A victim support worker listens, gives emotional support and counsels the victim. During the conversation they determine and assess the victims and their coping difficulties, and together with the victim they set goals and plan activities to better the victims' situation. Counselling helps the victim to understand their situation, make a decision and find necessary coping resources. The role of a victim support worker in the Estonian National Social Insurance Board, for the victims of human trafficking and minors and unaccompanied minors, who have fallen victims of sexual crimes, is to direct them to services in co-operation with service providers, and supervising them. In case of a violent crime, it is possible to seek national compensation for the victims (Ohvriabi seadus, 2003)1.

In Finland municipalities provide child welfare services and social workers are responsible for child welfare in municipalities. The Finnish Child Welfare Act applies to all children in Finland regardless of their background. In the Section 25 of the Child Welfare Act it is regulated that persons who work for example in social and health-care services and child day care, education services and the police service have a duty to notify the municipal body responsible for social services without delay and notwithstanding confidentiality provisions if, in the course of their work, they discover that there is a child for whom it is necessary to investigate the need for child welfare on account of the child's need for care, circumstances endangering the child's development, or the child's behaviour. Child Welfare Act also regulates that persons referred to in the section 25 have a duty, notwithstanding confidentiality provisions, to notify the police when they have cause to suspect on the basis of circumstances that have come to their knowledge an act of a sexual crime or a crime against life and health (minimum of two years penalty according to Criminal Code of Finland (39/1889) in cases of a suspect of a crime against life and health).

The goal of a currently ongoing project called LASTA is to create a national collaboration model for the police, the prosecution service, child protection authorities and healthcare (both somatic and psychiatric) for situations where one may suspect that a child is subjected to violence or sexual abuse. The LASTA project is a nationally coordinated and regionally managed development process involving several levels of management. The project is coordinated by the National Institute for Health and Welfare and supported by the Ministry of Social Affairs and Health, the Ministry of Justice and Ministry of the Interior.

The model consists of two steps. The first is about collecting necessary information for the purposes of the preliminary investigation and the handling of the case by the child protection service. The second step is about authorities gathering to evaluate the situation of the child. Essential background information on the child and his or her family is collected for the purposes of the preliminary investigation, evaluation of whether the child can be interviewed, evaluation of the severity of the violence, evaluation of the necessity of somatic examination, and protection and support for the child. The information is written on a special background information form. The form consists of a section on the suspected offence and sections on healthcare and child protection, respectively.

Based on the results of the development of LASTA it is recommended that firsly the process is initiated by a consultation request by the police to a coordinator employed for this purpose. After that the coordinator collects the information received. Finally the police organizes an interprofessional meeting to discuss the case.

1Ohvriabi seadus [Victim Support Act] (2003). Riigi Teataja I, 06.01.2016, 28. See: https://www.riigiteataja.ee/akt/12791909?leiaKehtiv 
During the interprofessional meeting, held once a week, those working on the case discuss the overall situation of the child from various points of view. Participants include the police officer and/or head investigator in charge of the case, a prosecutor, experts on somatic examination and child and adolescent forensic psychiatry, and experts on child psychiatry, crisis work, child protection and promotion of interests. This combination of professionals has been found highly effective in practice. ${ }^{1}$

Help to the victims of violence in Slovenia is organized regionally as well as locally. Every Slovenian region has formed a Regional service for coordination and assistance to victims. This regional service is responsible for assisting victims of violence, monitoring, implementing the intervention services 24 hours a day and cooperating. The regional service includes intervention 24 hour service, regional crisis centres and regional coordinator for the prevention of violence.

Locally, the key organization dealing with child victims of violence is the Centre for Social Work. In the case of child victims of violence, each organization and authority (including police) first have to inform the local centre for social work, which then continue to coordinate the treatment of victims. At each centre for social work, a multidisciplinary team is formed, which is responsible for:

1) Exchange of relevant information on the case;

2) Assessment of child at risk;

3) Assistance plan and coordination of activities;

4) Implementation of a plan to support the child.

Centres for social work mostly cooperate with the police, schools, kindergartens, health institutions, safe houses and other NGOs and with The Human Rights Ombudsman (Child Advocate). In most cases, the Centre for Social Work ex officio takes initiatives for inter-organizational co-operation. In very few cases, however, the initiatives are given by other organizations. Centres for Social Work operate interdisciplinary teams, look for adequate accommodation for the child (for example crisis centres), seek other forms of assistance to the child (for example therapeutic assistance and counselling) and participate in conferences, trainings and round tables.

Content of inter-organizational cooperation in schools with social work centers is linked to the participation in multidisciplinary teams in which they are invited by the Centre for Social Work. In cases in which they recognize a suspicion of violence against children, they are obliged to contact the Centre for Social Work by themselves. Content of co-operation between schools and other organizations in the field of assistance to child victims of violence is in mostly linked to the fulfilment of legal obligations. The most common co-operation with external organizations is in the field of prevention. NGO experts, carry out preventive anti-violence workshops and trainings for pupils, teachers and parents. Crisis centres and safe houses co-operate with the police and health services, home groups often with schools. They also give initiatives for inter-organizational cooperation, not only participating in the work of interdisciplinary teams in centres for social work.

In Spain there are currently two National Plans that involve a framework of co-operation between administrations and agents with regard to protection of minors and families. Specifically these National Plans are the 2 nd Strategic National Plan for Childhood Adolescence (PENIA, 2013-2016) and the Comprehensive Plan for Family Support (PIAF, 2015-2017). Both national plans define diverse strategic lines to follow for all the agents involved in bringing about the wellbeing of minors and families.

In Spanish system there are four agents responsible for safeguarding the best interests of minors: parents, citizens, professionals in different areas and institutions with legal powers with regard to minors. When the parents cannot guarantee the wellbeing of the minor or a situation of abuse is detected, the intervention of other institutions to protect the minor is necessary (Department of Social Welfare of the Government of Valencia, 2011). In these cases, six areas - education, health, social services, the police force, the legal system and civic organisations - must act in a coordinated manner to provide comprehensive attention to the diverse situations.

${ }^{1}$ More information: https://www.thl.fi/fi/web/lastensuojelun-kasikirja/tyoprosessi/erityiskysymykset/pahoinpitely-ja-seksuaalinenhyvaksikaytto/lasta-malli 
As a common framework to establish a procedure for childhood protection in the family environment in Spain, the Basic Intervention Protocol against Child Abuse in the Family Environment, developed by the Ministry of Health, Social Services and Equality (2014), is available (Ministry of Health, Social Services and Equality, 2014). The main objective of the current protocol is to promote inter-institutional coordination in order to improve the service provided to minors, avoiding the primary and secondary victimisation that they might suffer in the intervention process. The action protocol provides intervention guidelines for the various agents involved in the different phases of the intervention process: detection, notification, assessment, intervention and follow-up. Normally this coordination is carried out in writing, using different registers depending on the phase of the intervention process, area (social, educational, health, police and legal) and type of case (suspected abuse, gender violence, and mild, moderate or severe abuse).

In accordance with the phases of the intervention process and the Basic Intervention Protocol against Child Abuse in the Family Environment, detection and notification are two inextricable concepts given that detection leads to the subsequent notification. In this first phase, areas such as education, healthcare and police have an essential role detecting possible situations of abuse. After a detection of any sign of abuse, the notification must be made through a specific notification form for each of the action areas; to Social Services for the ordinary procedure and to Social Services and the Child Protection Service in the event of an urgent situation. Depending on the area and the case (ordinary or urgent) the notification must be made in the following way:

Social: when there is information that there may be a crime being committed against a minor or their mother, it must be communicated to the Magistrates' Court and Prosecution Services, and where appropriate to the State Security Forces and Bodies. If specialised gender violence or general social services are aware of a case of abuse, their duty is to communicate it to the relevant Child Protection Service, in accordance with the action protocols established in each Autonomous Community. In cases where the minor is witness to gender violence within the family, the situation must also be communicated to the leading gender violence body in the Autonomous Community. The notification is to be made in writing with telephone support. Furthermore, in case of an emergency the report of the allegation must be presented in writing and by telephone notification in less than 24 hours to both the Magistrates' Court and the prosecutors or specialised services within the State Security Forces and Bodies.

Education: faced with any suspicious case the management and counselling teams must complete the notification form, which will be referred to general social services. Faced with an urgent case, which requires health care, the minor must be accompanied to the health centre, Prosecution Services, the school inspection system, and to the minor's family, evaluating if it is harmful for them. Furthermore, a suspected crime must be communicated to the Magistrates' Court, the Police, Prosecution Services and the Child Protection Service.

Healthcare: when a health professional suspects a case of abuse, together with the Social Work Unit they must complete the notification form and refer it to Social Services. Furthermore, the report of injuries or the medical report is referred to the Magistrates' Court or Prosecution Services. In cases related to gender violence, "Common protocol for Healthcare Action faced with Gender Violence" guidelines will be followed.

Police: when situations of risk or social abandonment are confirmed, the facts will be communicated to the body responsible for child protection in each Autonomous Community, as well as Prosecution Services or Social Services. Depending on the type of case, different protocols must be adhered to.

Once a possible case of abuse has been detected in any area, an assessment of the situation must be carried out by social services (ordinary procedure) or the child protection body (urgent procedure). In the event of a case of abuse being confirmed, social services are responsible for centralising the intervention and requesting the collaboration of the rest of the areas wherever appropriate.

\section{Methodological Issues}

This paper analyses the situation in Estonia, Finland, Slovenia and Spain related to professionals' coordination challenges. Different methodology and instruments have been used such as desk research, focus groups, interviews and questionnaires to get an overview of the process in each country when child maltreatment cases are investigated. This section describes the methodology and instruments used in each country in order to gather information related to this issue. 


\section{Methodological issues in Estonia}

In order to identify the main limitations in coordination when it comes to child maltreatment cases, in Estonia a web questionnaire CAWI methodology with six open questions was used to find answers to the research questions shown in appendixes. The sample was $36(\mathrm{~N}=36)$ and the composition of the sample was made up of different professionals: $56 \%$ police oficers, $33 \%$ child protection workers and $11 \%$ victim support workers.

\section{Methodological issues in Finland}

In Finland telephone interviews were conducted in order to find out the main professionals' coordination challenges. The interview outline was made up of 7 open-ended questions to gather qualitative data (See appendixes). The interview was conducted to five profesionals from different fields such as kindergarten, social services and healthcare and judicial authorities in order to learn about their experiences.

\section{Methodological issues in Slovenia}

In Slovenia they analysed professional coordination was based on desk research by analysising online sources about current legislative framework, policies and national strategies and personal interviews. In particular 15 interviews were conducted to: 6 counsellors of centers for social work, 3 schools counsellors and with 6 experts from non-governmental organizations belonging to home group for children and youth, a safe house, a crisis center for children and adolescents, a SOS phone for children and philanthropic organizations.

\section{Methodological issues in Spain}

In order to obtain information about the main challenges in the coordination of the protection system a focus group was formed with eight professionals from the social sector in Spain (See appendixes). The focus group conducted was made up of eight professionals with the aim of gathering several opinions (Ibáñez, 1979; Krueger, 1991; Canales and Peinado, 1995; Callejo, 2001). The session of the focus group in Spain was structured and developed following the intructions of Llopis (2004).

\section{Results from the Analysis}

This section shows the results obtained related to the principal difficulties or areas to be improved in the coordination of the child protection system in Estonia, Finland, Slovenia and Spain.

As for the main c-ooperation partner, the results in Estonia show that police has been the main co-operation partner for child protection workers as well as for victim support workers. However, on the basis of the opinions of the respondents in this research, it seems that there is no mutual co-operation between child protection workers and victim support workers since they did not mention each other as co-operation partners. As regard networking, the results show that professionals' knowledge about the work done with a child victim and networking is generally good. Nevertheless, more knowledge should be gained in some areas such as information concerning the competence and duties of other network members. While police officers encounter child victims the most since oftentimes they are the first specialists, who meet the child at the beginning of the case, child protection workers and victim support workers receive more information through other members of the network and deal with a child's natural social network more often. Regarding knowledge needed by professionals, the results indicate that how to act with the victim at the beginning of the case, communicate with parents and motivate them to co-operate are sensitive areas when intervening in a case of child maltreatment. Thereby, professionals highlighted that more training is needed in order not to forget about existing knowledge and because working with victims is a field continuously changing where it is important to be up to date.

In Finland the results have shown that interprofessional collaboration was considered to be working well on the whole. However, certain restraints, such as rapidly changing teams caused by short-term contracts, were considered challenges for the proper functioning of interprofessional collaboration. Moreover, according to the results obtained, the exchange of information between professionals is often feared for wrong reasons, making professionals hesitant to intervene in child maltreatment cases at an early stage. Thus, developing the exchange of information and the courage to act at an early stage was considered an area of future improvement. As for the potential knowledge needed by professionals, sexual crime and how to work with the victims were areas stressed out. 
In Slovenia, according to the interviews, philanthropic institutions pointed out that, in practice, inter-organizational cooperation in the field of treatment of child victims of violence is not optimally. It is believed that, the flow and exchange of information between organizations involved in such cases is often poor and too general. Thereby, minutes of interdisciplinary team meetings do not contain any substantive description of the case and bodies and non-governmental organization cannot deal with the case appropriately which significantly reduces the chances of a successful assistance and protection to victims. As for centres for social work, they are satisfied with the co-operation of the police and nongovernmental organizations but less satisfied with health organizations, such as paediatricians, psychiatrists and doctors. As stated by centres for social work counsellors, representatives of health institutions rarely participate in interdisciplinary teams. In addition, the results showed that level of co-operation with the judiciary system is low due to difficult availability of judges, prosecutors, etc. Besides, the findings suggest that the level of co-operation between centres for social work outside the major cities and philanthropic organizations is lower since NGOs are found primarily in major cities, or NGOs do not have a sufficient number of staff to co-operate in multidisciplinary teams outside their office city. With respect to the education field, the results showed that schools are trying to solve the occurrence of cases of violence within the organization as much as possible, except in cases where an application under the law is necessary. They are mostly engaging in interdisciplinary teams initiated by the Centre for Social Work, but less by their own initiatives, even if the school counsellors can deal with cases of violence in the extended teams initiated by the school. Also, it was suggested by schools that there is high satisfaction with the co-operation with non-governmental organizations.

In Spain, the results have shown that some cases of child abuse are not referred to social services, the institution responsible for centralising the intervention. This principally occurs in cases of intra-family gender violence since they are normally served by other services or specific gender violence programmes. Additionally it was noted that the established Protocol for coordination in these cases is not followed in all areas. This is highlighted in particular in the policing sector, where the police report is used instead of the notification forms as a record, which may affect potential coordination between areas. Thereby, with regard to the notification forms, professionals point out a lack of training about how they work. Thus, while the effort of authorities to encourage coordination between areas using these forms is highlighted, there seems to be a limited effort on behalf of the administration to disseminate the use of the forms. Therefore some professionals are not aware of how they work, limiting the potential of this instrument, in particular in the education sector. The findings suggested that the non-use of notification forms in the education sector makes different situations of abuse more difficult to detect. Furthermore, detection could be more complicated if it is less evident or if another type of variable comes into play, such as the fear of reporting or the attitude towards abuse of the professionals themselves. Furthermore, the results highlighted an especially worrying limitation or gap in the coordination system between the education, healthcare and social sectors. In particular it was pointed out that cases of neglected 6-year-old minors, due to hygiene or nutrition problems detected in the healthcare sector, went unnoticed during primary education by the education sector and social services, making their intervention impossible. These cases are not detected again unless the minors develop patterns of antisocial behaviour at school, when social services are notified for their intervention. On the whole, according to the Spanish results, coordination is sometimes understood as a voluntary act rather than an obligation among certain professionals.

\section{Conclusions}

In order to help a child victims quickly and effectively, it is important that different specialists co-operate with each other as every specialist has their own role and opportunities to support the child in co-operation networking. With the intention of making sure that no child in need of assistance would go unnoticed and without help, the skill of co-operating is of high importance. Thus, changing of information between specialists is crucial to recognize the victims at early stage and gather as much information as possible to get the full picture of the situation.

To this end, the purpose of this paper has been to analyse professionals' coordination challenges in Estonia, Finland, Slovenia and Spain. In doing so, different methodology and instruments have been used such as desk research, focus groups, interviews and questionnaires to get an overview of the process in each country when child maltreatment cases are investigated.

The results have shown that the main problems and areas which need improvement are quite similar in every country. Thereby, one detected problem is the tendency of the professionals to intervene only at a relatively late stage. This fact could be related to other problems such as fear of reporting the cases or the difficulty of recognizing victims. Hence, the results have shown that more attention should be paid to issues such as how to recognize the victims and how to act with them when there is suspect of maltreatment. 
As different authorities must co-operate when a case of child maltreatment occurs, the results have shown different levels of co-operation between professionals from different areas. Generally speaking, the findings suggest that there is a good level of co-operation between social workers and the police in each country in most of the cases but, on the whole, less cooperation is identified with the healthcare workers.

In addition, the results have shown that although co-operation among professionals is a duty, sometimes it is regarded as a voluntary action due to the lack of time or information concerning the competence and duties of other network members. According to the results, the lack of discussion and the lack of trust with other professionals can be seen as a big problem in co-operation. Thus, the results suggest that creating good relationships and putting emphasis on other professionals' strengths are key elements when it comes to good co-operation.

In conclusion, the present research has contributed to highlight that additional training for professionals working with children is required. This could be helpful to boost professionals' confidence to intervene at as early a stage as possible when a case of child maltreatment occurs and to exchange the knowledge among professionals. In addition, reinforcing the co-operation among professionals might prompt share best practices among professionals and broad the knowledge about the competences and duties of other network members.

Therefore, it is considered that results reached in this study show a significant insight into the necessity to reinforce cooperation among professionals as it is associated with achieving common goals as well as trusting networking partners.

\section{References}

[1] Bartolomé, J. C. (2013). La poliédrica y heterogénea protección internacional de los menores. Revista sobre la infancia y la adolescencia, 4, 1-27. DOI: http://dx. doi. org/10. 4995/reinad. 2013. 1462.

[2] Callejo, J. (2001). El grupo de discusión: introducción a una práctica de investigación. Barcelona: Ariel.

[3] Canales, M., \& Peinado, A. (1995). "Grupos de discusión". En Delgado, J. M. y Gutiérrez, J. (coord. ): Métodos y técnicas cualitativas de investigación en ciencias sociales. Madrid: Editorial Síntesis, p. 287 - 316.

[4] Department of Social Welfare of the Government of Valencia (2011). El papel del ámbito de los Servicios Sociales en la detección y abordaje de las situaciones de desprotección o maltrato infantil. Valencia: Generalitat Valenciana.

[5] Haage, B. (2015) Lasteaedade ja kohaliku omavalitsuse koostöö Nõmme linnaosa näitel: abivajavast lapsest teavitamine. Tallinna Ülikool

[6] Heinonen, A. (2015). The construction of disciplinary violence against children - social workers, police officers and parents rationales. Retrieved from: https://www. thl. fi/fi/web/lastensuojelun-

kasikirja/tyoprosessi/erityiskysymykset/pahoinpitely-ja-seksuaalinen-hyvaksikaytto/lasta-malli.

[7] Ibáñez, J. (1979). Más allá de la sociología. El grupo de discusión: técnica y crítica. Madrid: Siglo XXI.

[8] Krueger, R. A. (1991). El grupo de discusión. Guía práctica para la investigación aplicada. Madrid: Editorial Pirámide.

[9] Llopis, R. (2004). El grupo de discusión: Manual de aplicación a la investigación social, comercial y comunicativa. Madrid: ESIC Editorial.

[10] Martínez-Molina, S. et al. (2016). Challenging issues facing the professionals of child protection in Estonia, Finland, Slovenia and Spain: a comparative study. European journal of social sciences education and research, 8,1, 156-169.

[11] Ministerio de Sanidad, Servicios Sociales e Igualdad (2013). II Plan Estratégico Nacional de Infancia y Adolescencia 2013-2016. Retrieved from:http://www. observatoriodelainfancia. msssi. gob. es/documentos/pdf/IIPLAN_ESTRATEGICO_INFANCIA. pdf 
[12] Ministerio de Sanidad, Servicios Sociales e Igualdad (2014). Protocolo básico de intervención contra el maltrato infantil en el ámbito familiar. Retrieved from: http://www. observatoriodelainfancia. msssi. gob. es/productos/pdf/Maltratolnfantil_accesible.pdf

[13] Ministerio de Sanidad, Servicios Sociales e Igualdad (2015). Plan Integral de Apoyo a la Familia PIAF (20152017). Retrieved from: http://www. msssi. gob. es/novedades/docs/PIAF-2015-2017. pdf

[14] Ohvriabi seadus [Victim Support Act] (2003). Riigi Teataja I, 06. 01. 2016, 28. Accessed 22 June 2016, at: https://www. riigiteataja. ee/akt/12791909?leiaKehtiv

\section{Appendixes}

\section{1 Estonian research questions}

The questionnaire which was administrated in Estonia was the following:

1. How do the respondents describe a child victim?

2. What kind of experiences do the respondents have in networking between each other?

3. How do the respondents assess their knowledge of child victims and networking?

4. What is the role of a co-operation partner in noticing and helping a child victim?

5. What are some of the factors that support or constrain effective co-operation, and what has been the contribution of the respondents in developing networking?

6. What kind of experience do the respondents have so far in international networking with child victims?

\section{2 Interview questions in Finland}

The Finnish extract of interview was the following:

1. Your profession

2. What kind of child maltreatment have you encountered in your work?

3. What do you do if you receive information that a child may be subjected to maltreatment?

4. In your view, how well has interprofessional collaboration worked when investigating cases of child maltreatment?

5. Do you feel that you are receiving sufficient support from your colleagues when working with cases of child maltreatment?

6. What are, in the context of your particular work, the greatest challenges when dealing with cases of child maltreatment?

7. What kind of additional training would you like to receive on the topic of child maltreatment?

\section{3 Spanish focus group professionals' profiles}

The Spanish focus groups was made up of the following professionals:

Two social workers from municipal social services

A psychologist from family, minors, and youth Section from a local administration

A psychologist from a philanthropic organization

A social worker from a philanthropic organization

A psychologist from a centre for minors

A social worker working in a hospital

A regional manager of a philanthropic organization 


\section{4 Focus group in Spain}

The session of the focus group in Spain was developed and structured according to Llopis (2004) instructions and it was structured as follows:

\section{Introduction}

Moderators introduction

Introduction institution

Objectives of the meeting

Topic of the meeting

Confidentiality and recording of the meeting

Rules of the meeting

Several opinions, consensus is not needed

There is not an absolute truth

Not to interrupt

Honest answers

\section{Introduction of Participants}

Name

Institution

Position

Warm-up Discussion (Difficulties in a Hypothetical Case of Child Maltreatment)

Detection

Notification

Intervention

Professionals coordination

Free Discussion.

Skills self-learned

\section{Topics to Discuss}

Current training deficiencies

Description of courses taken that have been helpful

Type of future training 